\title{
Spaceborne L-band Radiometers: Push-broom or Synthetic Aperture?
}

\section{Skou, Niels}

\section{Published in:}

Proceedings of IGARSS'04

Link to article, DOI:

10.1109/IGARSS.2004.1368646

Publication date:

2004

Document Version

Publisher's PDF, also known as Version of record

Link back to DTU Orbit

Citation (APA):

Skou, N. (2004). Spaceborne L-band Radiometers: Push-broom or Synthetic Aperture? In Proceedings of IGARSS'04 IEEE. https://doi.org/10.1109/IGARSS.2004.1368646

\section{General rights}

Copyright and moral rights for the publications made accessible in the public portal are retained by the authors and/or other copyright owners and it is a condition of accessing publications that users recognise and abide by the legal requirements associated with these rights.

- Users may download and print one copy of any publication from the public portal for the purpose of private study or research.

- You may not further distribute the material or use it for any profit-making activity or commercial gain

- You may freely distribute the URL identifying the publication in the public portal

If you believe that this document breaches copyright please contact us providing details, and we will remove access to the work immediately and investigate your claim 


\title{
Spaceborne L-band Radiometers: Push-broom or Synthetic Aperture?
}

\author{
Niels Skou \\ Oersted $\bullet$ DTU, B 348, \\ Technical University of Denmark. \\ DK 2800 Lyngby, Denmark. \\ Phone: (45) 452538 00, Fax: (45) 45931634 \\ e-mail: ns@oersted.dtu.dk
}

\begin{abstract}
L-band radiometers can measure ocean salinity and soil moisture from space. A synthetic aperture radiometer system, SMOS, is under development by ESA for launch in 2007. A real aperture push-broom system, Aquarius, has been approved by NASA for launch in 2008. Pros et cons of the two fundamentally different imaging concepts behind the two missions are discussed.
\end{abstract}

\section{INTRODUCTION}

Spaceborne L-band radiometer systems have for decades been known to enable global measurements of sea surface salinity and of soil moisture. Concurrently it has been fully recognized that knowledge of these two geophysical parameters are extremely important as input to global circulation and climate models - but unfortunately not measured to any satisfactory level of spatial coverage. Such measurements can for practical reasons only be carried out from space, so why has this not happened until now? The reason is that salinity and soil moisture can only be measured at frequencies at the low end of the microwave spectrum, in practice L-band around $1.4 \mathrm{GHz}$, and for any reasonable ground resolution this means large antenna apertures, that has been deemed unrealistic. That is: until now where the necessary concepts and technology are available.

Large structures are difficult to handle in space and expensive to launch. Especially mechanically scanned antennas are difficult. Thus imaging systems without the need for physical scanning has been proposed:

In the push-broom concept a special antenna, having many simultaneous beams each associated with its individual feed and receiver, is employed. When the satellite moves forwards the beams sweep the Earth's surface like a broom and make an image without scanning. The many receivers ensure the ultimate in radiometric sensitivity. The price to pay is: many receivers as well as a complicated and large antenna. However, present day receivers made as MMICs are small and low power units, and foldable reflector structures that works well at L-band are possible using proven technology.

The synthetic aperture radiometer works as a radio camera and acquires a two-dimensional image of the ground by interferometric means. As the satellite moves forwards a swath is imaged. Again, many receivers (and antenna elements) are needed. The big advantage is that a relatively slim structure - the antennas can for example be positioned along 3 arms arranged in a Y shape - can be used, and the structure is easily foldable. A drawback is substantial data processing requirements and less straight forward calibration issues.

\section{WHERE SCANNERS CANNOT DO THE JOB}

Traditionally, an imaging spaceborne radiometer features a mechanical scanning in which a parabolic antenna reflector is physically rotated around an axis. For Earth surface sensing this is normally a vertical axis, and a conical scan with constant incidence angle on ground results [1]. The antenna reflector can serve a range of frequencies, and the result is often a compact and efficient system, and as such has been a very successful concept. Many multi-frequency systems ranging from SMMR launched in 1978 to the SSM/I and TMI family of today substantiate this.

But the concept has severe constraints coming from the fact that all data at a given frequency normally is time multiplexed through one single receiver. This means that if a small footprint on the ground is required, the scan speed is large, the dwell time per footprint is small, hence the radiometer integration time is short and the potential radiometric sensitivity possibly not satisfactory. The large scan speed in itself is also a challenge (for the satellite constructers). For a typical scanner operating from $800 \mathrm{~km}$ orbit with $53^{\circ}$ incidence angle on ground it is straight forward to calculate the integration time $\tau=\mathrm{FP}^{2} / 73.5$ (msec) and the antenna rotation rate $\omega=441 / \mathrm{FP}(\mathrm{rpm})$ where FP is the footprint in $\mathrm{km}$. For a push-broom system operating under the same conditions one finds $\tau=136$ FP (msec). When FP becomes small the difference between $\tau$ of the two concepts becomes dramatic.

The brightness temperature of the ocean does indeed depend on the salinity as for example pointed out in the classical reference by Klein \& Swift [2], but the sensitivity to salinity combined with the oceanographers requirements to salinity resolution in order to be of use, results in a severe requirement to radiometric resolution, around $0.1 \mathrm{~K}$.

The oceanographers ground resolution (FP) requirements are less stringent: over the open ocean, salinity changes slowly over hundreds of $\mathrm{km}$, while in special areas like the 
Gulf stream, and nearer the coastlines, resolution down to 10 $\mathrm{km}$ would be of value, yet impossible as this leads to antenna apertures of $30 \mathrm{~m}$.

An L-band radiometer system has also a unique capability to measure soil moisture, so a combined ocean salinity / soil moisture satellite mission is of course a highly appreciated dual use concept. Radiometric resolution requirements over land are limited and $1 \mathrm{~K}$ can do quite well, but a ground resolution of hundreds of $\mathrm{km}$ is of little use. It is generally accepted that a $50 \mathrm{~km}$ footprint would be very valuable as this fits the grid size of the present climatology and meteorology models - and soil moisture input to these models is actually of paramount interest.

A $50 \mathrm{~km}$ footprint requires a $10 \mathrm{~m}$ antenna aperture (800 $\mathrm{km}$ orbit, $53^{\circ}$ incidence) which is ambitious but realistic with present day technology. Inserting $\mathrm{FP}=50 \mathrm{~km}$ in the formulas stated above leads for the scanner to $\tau=30 \mathrm{msec}$ and $\omega=9.4$ $\mathrm{rpm}$. The $30 \mathrm{msec}$ may not sound too bad, but combined with the small bandwidth available within the protected band $(1400-1427 \mathrm{MHz})$ and realistic receiver performance, the result is a radiometric sensitivity of $\Delta \mathrm{T}=0.4 \mathrm{~K}$ which does not fulfill the requirements. At the same time rotating a $10 \mathrm{~m}$ reflector with $9.4 \mathrm{rpm}$ on a satellite is no easy task! For the push-broom case one finds $\tau=6.4 \mathrm{sec}$ which is quite another story leading to a $\Delta \mathrm{T}=0.08 \mathrm{~K}$.

It is clear that a scanner is not suited for such a mission, while the push-broom certainly is.

\section{A REALISTIC PUSH-BROOM SALINITY SENSOR}

In the following a 21 channel L-band push-broom radiometer system will be presented and discussed. Some specifications are:

- Frequency: $1404-1423 \mathrm{MHz}$

- Dual polarization: H \& V

- Antenna aperture: $10 \mathrm{~m}$

- Satellite altitude: $800 \mathrm{~km}$

- Incidence angle on ground: $53^{\circ}$

- Swathwidth: $530 \mathrm{~km}$

- Footprint: $47 \mathrm{~km}$ (actually 36 x $60 \mathrm{~km}$ )

- Radiometric resolution: $0.08 \mathrm{~K}$

The specifications are chosen according to the discussion in the previous section, but also to be close to the specifications of the SMOS instrument to be presented in the next section.

Figure 1 illustrates the system. 21 feeds illuminate the reflector which is in the shape of a torus in order to satisfy the need for a structure that is rotationally symmetric around a vertical axis and hence is able to cover a wide swath with constant incidence angle. For practical reasons the feeds (here shown as horns) must be arranged in two rows, since their physical size exceeds the distance between positions required for proper beam squinting corresponding to correct footprint position on ground.

Figure 2 shows a photo of a demonstration model scaled to a frequency of $36.5 \mathrm{GHz}$. The instrument was flown in conjunction with a mechanically scanned imager having the same ground resolution in order to validate the push-broom concept [3].
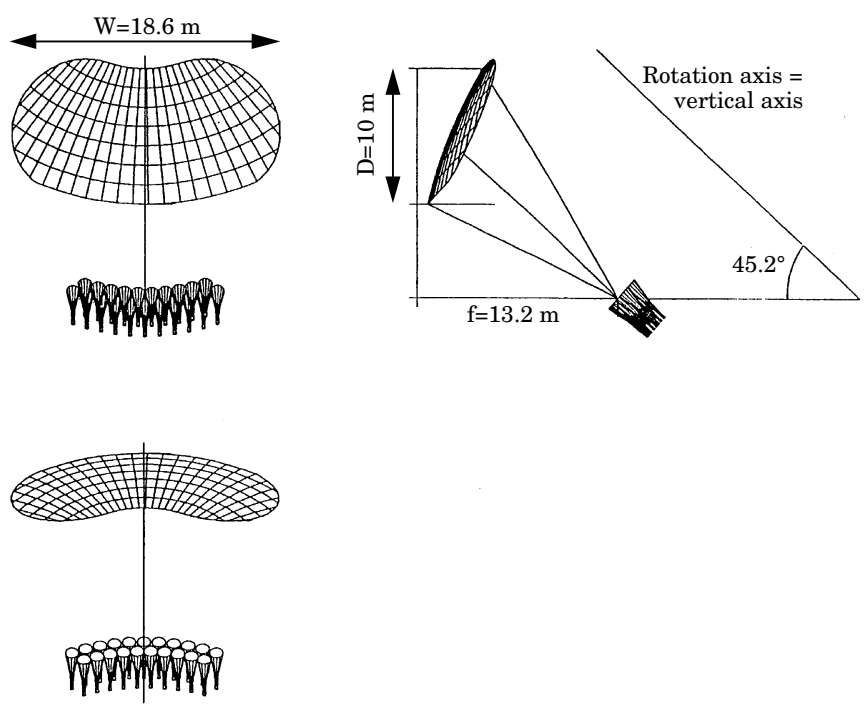

Figure 1: Push-broom torus antenna with 21 feeds.

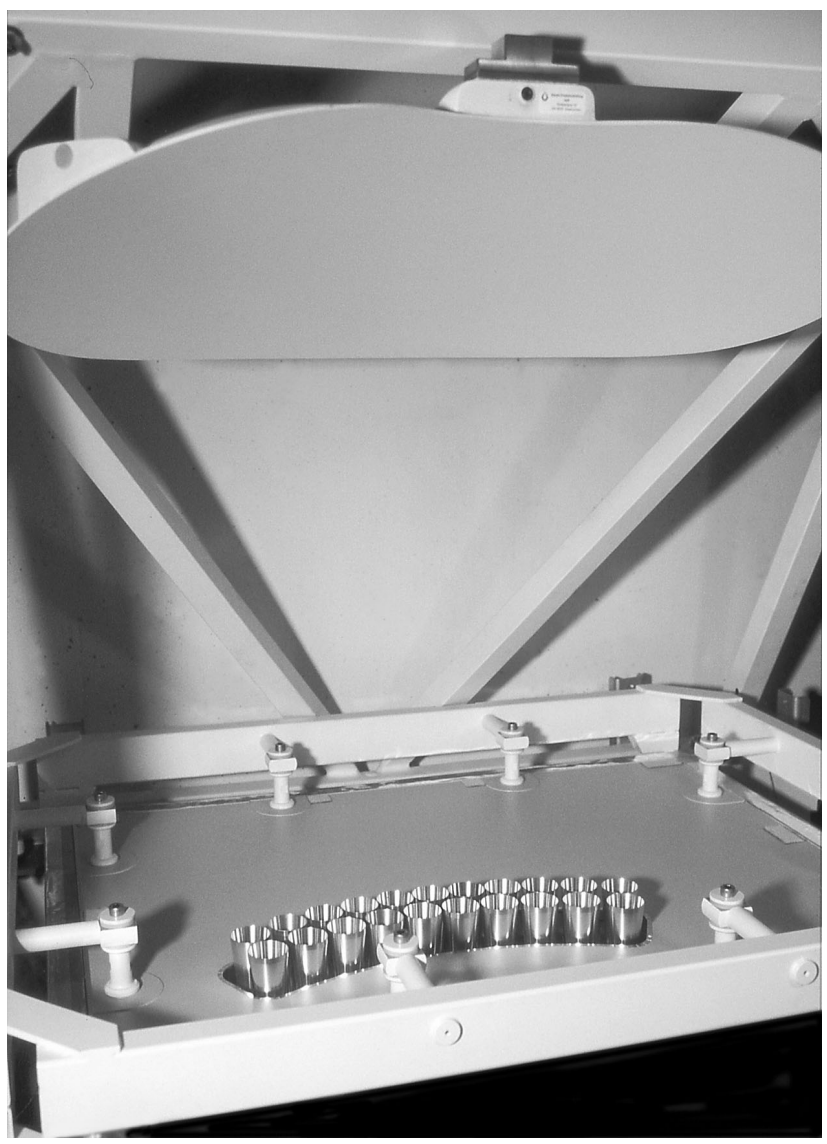

Figure 2: The push-broom demo system.

The feeds are connected with 42 noise-injection receivers in order to go for the best possible stability and accuracy. In a push-broom radiometer all receivers are constantly busy 
sensing the Earth, so calibration means loss of data. Hence calibration should only be made as often as necessary, and the noise injection radiometer being the most stable radiometer concept is the candidate receiver type.

Based on experience with making compact, light, and power efficient radiometers at microwave frequencies using state-of-the-art MMIC technology, an L-band noise-injection radiometer can be assumed to have a weight of $500 \mathrm{~g}$ and consume $2 \mathrm{~W}$ of power.

For many years the huge antenna structures as considered here has been an insurmountable problem! But substantial developments have taken place recently, and now there is no doubt about the feasibility. A $12 \mathrm{~m}$ mesh antenna, having a weight of $85 \mathrm{~kg}$ and being able to serve an L-band radiometer, has been flown in space [4]. A communication satellite having two $19 \times 17 \mathrm{~m}$ antennas has been designed and the antennas demonstrated. Based on these numbers, a $10 \times 19 \mathrm{~m}$ mesh antenna for the present purpose could have a weight of around $150 \mathrm{~kg}$ including feed mast and structure.

The feeds require a few comments. So far, horn antennas have been assumed as feed elements, and indeed the scaled demo model shown in Figure 2 employs horns. For the spaceborne instrument it must be realized that horns become very big, in the present case with an aperture around $80 \mathrm{~cm}$ and of considerable length. Such horns can be fabricated as light and stiff structures, but the weight per unit will probably be around $10 \mathrm{~kg}$, in total for the horns: $210 \mathrm{~kg}$.

An alternative to the horns is microstrip patch antennas. In general these will have higher losses than horns do, but considering the considerable bulk of the horns it may well be an option worth investigating.

Calibration of the system is an important task, but since traditional radiometers are used, the task is well understood and ways of doing it with great fidelity can be outlined, see $\mathrm{f}$. ex. [1].

Finally, a weight and power budget shall be outlined: the weight of the total system is assumed to be $392 \mathrm{~kg}$ ( $150 \mathrm{~kg}$ for the antenna, $210 \mathrm{~kg}$ for feeds, $21 \mathrm{~kg}$ for the receivers, $11 \mathrm{~kg}$ for misc electronics); the power consumption of the system is assumed to be $112 \mathrm{~W}$ ( $84 \mathrm{~W}$ for receivers, $10 \mathrm{~W}$ for data handling, $18 \mathrm{~W}$ for power supply).

\section{SMOS}

In the synthetic aperture case it is actually so that the discussion can be based on a real instrument presently being developed by ESA for launch in 2007, and although the system is not yet cast in concrete, most specifications are quite fixed by now. SMOS is synthesizing a ground resolution corresponding to a roughly $9 \mathrm{~m}$ real aperture antenna by cross correlating signals from all possible pairs of small antenna elements suitably positioned within that aperture [5].

SMOS is a $1.4 \mathrm{GHz}$ system with 69 antenna elements and radiometers mounted on three $4.3 \mathrm{~m}$ long arms as well as on a central hub, that also holds the many correlators - one for each possible pair of antennas. See Figure 3. Three of the elements in the central hub are actually connected to very accurate noise injection radiometers (NIR) in order to measure the absolute level of the brightness temperature scene being sensed.

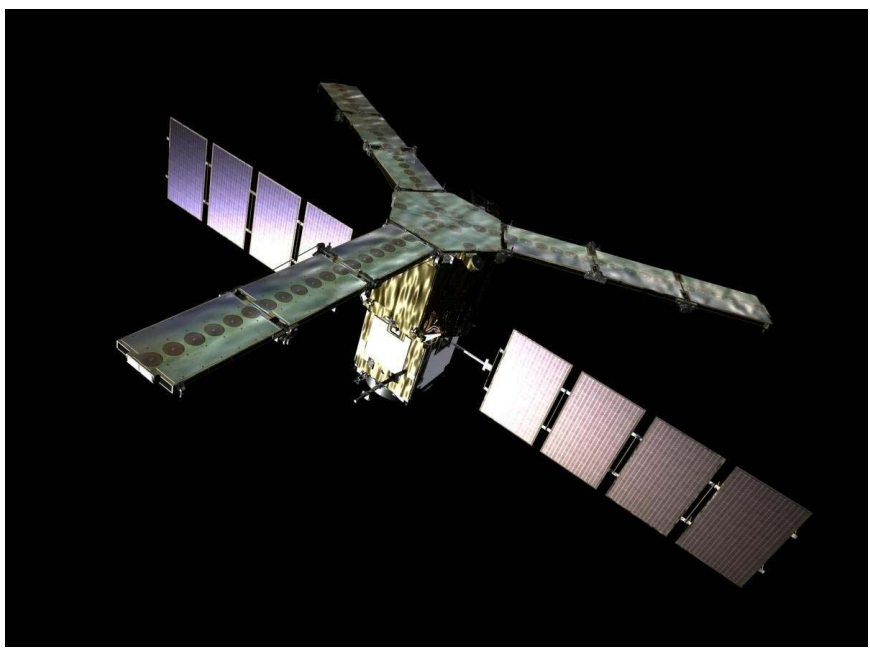

Figure 3: SMOS in deployed state

It is obvious that the amount of real estate required is much less than for a normal radiometer, and also it is seen to be relatively straight forward the fold the structure for launch (each arm consist of 3 hinged sections).

Some specifications are:

- Dual polarization: $\mathrm{H} \& \mathrm{~V}$ (and polarimetric)

- Satellite altitude: $755 \mathrm{~km}$

- Incidence angle on ground: $0-55^{\circ}$

- Swathwidth: about $800 \mathrm{~km}$

- Footprint: about $50 \mathrm{~km}$

- Radiometric resolution: $2.4 \mathrm{~K} / 0.4 \mathrm{~K}$

Many of these specifications can actually not be quoted as single numbers, due to the way SMOS acts as a radio camera making two-dimensional images of the ground, see Figure 4.

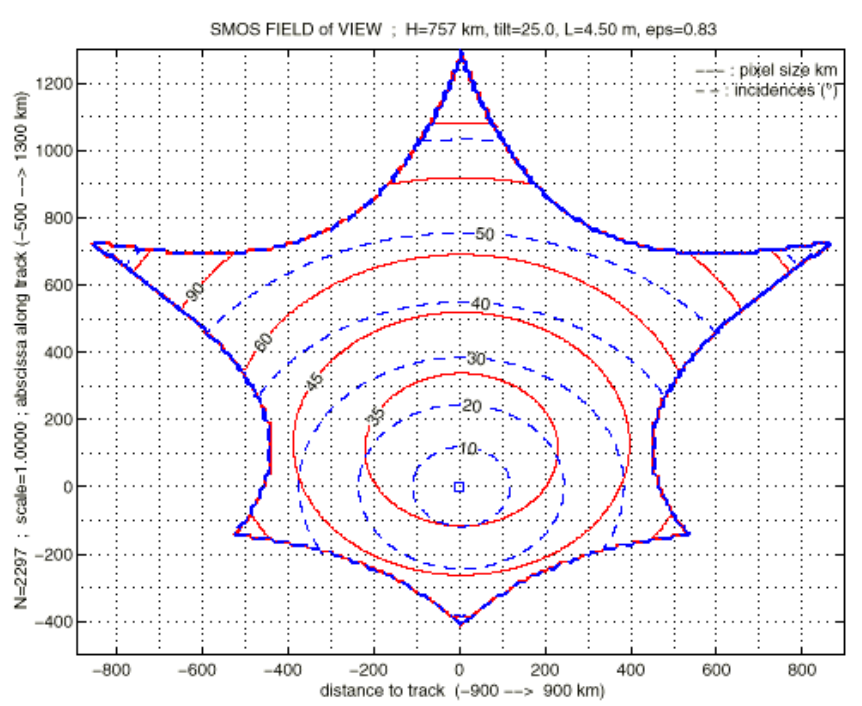

Figure 4: Illustration of SMOS coverage (some parameters slightly off baseline) 
It is seen that within a swath of roughly $800 \mathrm{~km}$ all points on ground are covered with a variety of incidence angles (curves numbered $10,--50^{\circ}$ ) and footprints (curves numbered $35,-90 \mathrm{~km}$ ) as they move through the star shaped coverage pattern. This also means that two different radiometric resolutions are quoted, namely the snapshot value of $2.4 \mathrm{~K}$, and the value after proper integration along track.

The fact that each point in the swath is imaged with a variety of incidence angles is actually one of the great strengths of the two-dimensional imaging concept: due to the fact that geophysical targets have brightness temperatures featuring different dependencies on incidence angle, multiparameter retrievals are possible.

The synthetic aperture concept is based on the fact that by measuring an adequate number of the so-called visibilities, the original brightness temperature map can be found by an inverse Fourier transform (in the ideal case). The visibilities are in principle outputs of the correlators operating on the outputs of pairs of antenna + radiometer elements. The visibility function corresponding to a pair of channels 1,2 is shown in the following equation where: $\mathrm{k}$ is Boltzman's constant, $B_{1,2}$ are the noise bandwidths of the channels, $G_{1,2}$ are the power gains of the channels, $\left\langle b_{1} b_{2}{ }^{*}\right\rangle$ is the correlator output, $\Omega_{1,2}$ are the equivalent solid angle of the normalized radiation patterns of the antennas, $\mathrm{T}_{\mathrm{B}}$ is the brightness temperature scene to be sensed, $(\xi, \eta)$ are the directional cosines, $\mathrm{F}_{\mathrm{n} 1,2}$ are the normalized radiation patterns of the antennas, and $r_{1,2}$ is the fringe wash function accounting for decorrelation effects.

$$
\begin{aligned}
& V_{1,2}=V\left(u_{1,2}, v_{1,2}\right)=\frac{1 / 2}{k \sqrt{B_{1} \cdot B_{2}} \cdot \sqrt{G_{1} \cdot G_{2}}} \cdot\left\langle b_{1}(t) b_{2}{ }^{*}(t)\right\rangle= \\
& \frac{1}{\sqrt{\Omega_{1} \cdot \Omega_{2}}} \cdot \iint \frac{T_{B}(\xi, \eta)}{\sqrt{1-\xi^{2}-\eta^{2}}} \cdot F_{n 1}(\xi, \eta) \cdot F_{n 2}^{*}(\xi, \eta) \\
& \cdot \widetilde{r}_{1,2}\left(-\frac{u_{1,2} \cdot \xi+v_{1,2} \cdot \eta}{f_{o}}\right) \cdot e^{-j 2 \pi\left(u_{1,2} \cdot \xi+v_{1,2} \cdot \eta\right)} d \xi d \eta
\end{aligned}
$$

It is seen that to obtain the correct value for the visibility function from the measured correlation, and subsequently the correct value of the brightness temperature from the visibility samples, many system parameters have to be accurately known. Especially, it can be mentioned that the antenna patterns have to be known to an accuracy of $0.05 \mathrm{~dB}$ and $0.33^{\circ}$ in phase.

Calibration of radiometers is never a task that can be taken lightly, but for real aperture radiometers the methods and means are at least easily understandable and available. But as should be clear from the above, calibration of synthetic aperture radiometers is a very different undertaking, and conceptually far from simple. The methods and means are now available, but it is fair to recognize that calibration of synthetic aperture radiometer systems is a complicated task still under development and refinement within the radiometer community.

A crude weight and power budget for the SMOS payload is: $330 \mathrm{~kg}$ and $220 \mathrm{~W}$.

\section{DISCUSSION \& CONCLUSIONS}

Comparing push-broom and synthetic aperture radiometer systems is no simple task as they are so different - and not just in the way they work and are implemented, but also in the output product they generate.

The main virtues of the push-broom system are that it gives superior radiometric resolution and very likely also superior accuracy and stability.

The main virtues of the synthetic aperture system is that it measures the brightness temperature as a function of incidence angle, and that it is relatively straight forward to fold it for launch.

Concerning weight and power the differences are not large enough to be fundamental for the choice.

The virtues of the push-broom system might point towards use in cases with extreme requirements to radiometric resolution and accuracy, like in the case of ocean salinity. The virtues of the synthetic aperture system, on the other hand, point towards use in cases with complicated targets like vegetation covered soil, where it is possible to retrieve soil moisture, cleaned for the vegetation influence, due to the multi-incidence angle imaging.

It is noted that the newly introduced NASA mission, Aquarius, focuses on ocean salinity, and is implemented as a push-broom instrument [6]. Although it is a "simple" pushbroom system compared with the one discussed here in this paper (it only has 3 beams) it will demonstrate all the virtues of such a system once in space (apart from pixel numbers). SMOS, although a dual-purpose mission, has its largest focus on soil moisture (SMOS will be deemed a success if it handles soil moisture well), and is implemented as a synthetic aperture system.

It will be interesting in the near future to compare the outcome of the two missions!

\section{REFERENCES}

[1] N. Skou: "Microwave Radiometer Systems: Design and Analysis", Artech House, 1989

[2] L. A. Klein and C. T. Swift: "An Improved Model for the Dielectric Constant of Sea Water at Microwave Frequencies", IEEE AP, Vol. 25, No. 1, pp $104-111,1977$.

[3] N. Skou, S. S. Kristensen: "Comparison of Imagery from a Scanning and a Push-broom Microwave Radiometer", Proc. IGARSS'91, pp $2107-2110,1991$

[4] www.Astro-Aerospace.com

[5] www.esa.int/export/esaLP/smos.html

[6] http://aquarius.gsfc.nasa.gov/ 